\title{
Softec HD hydrophilic acrylic intraocular lens: biocompatibility and precision
}

This article was published in the following Dove Press journal:

Clinical Ophthalmology

7 January $201 \mathrm{I}$

Number of times this article has been viewed

\author{
Ladan Espandar' \\ Shameema Sikder ${ }^{2}$ \\ Majid Moshirfar ${ }^{3}$ \\ 'Department of Ophthalmology, \\ Tulane University, New Orleans, \\ LA, USA; ${ }^{2}$ Wilmer Eye Institute, \\ Johns Hopkins University, Baltimore, \\ MD, USA; 3 John A Moran Eye Center, \\ University of Utah, Salt Lake City, \\ UT, USA
}

\begin{abstract}
Intraocular lens development is driven by higher patient expectations for ideal visual outcomes. The recently US Food and Drug Administration-approved Softec HD ${ }^{\mathrm{TM}}$ lens is an aspheric, hydrophilic acrylic intraocular lens (IOL). The hydrophilic design of the lens is optimized to address dysphotopsia while maintaining biocompatibility, optical clarity, resistance to damage, and resistance to biocontamination. Aspheric lenses decrease postoperative spherical aberration. The addition of the Softec lens provides clinicians with another option for IOL placement; however, randomized comparative studies of this lens to others already on the market remain to be completed.
\end{abstract}

Keywords: hydrophilic acrylic intraocular lens, Softec HD intraocular lens, aspheric intraocular lens, IOL

\section{Overview}

The Softec HD ${ }^{\mathrm{TM}}$ posterior chamber intraocular lens (Lenstec Inc., St. Petersburg, FL, USA) is an ultraviolet (UV)-absorbing, single-piece modified "C" loop intraocular lens (IOL) with a symmetrical anterior and posterior surface aspheric design (zero aberration) (Figure 1). The Lenstec Softec HD IOL is manufactured completely from a medical-grade copolymer of hydrophilic acrylic hydroxyethylmethacrylate (HEMA, $26 \%$ water content) and a polymerizable UV blocker. The overall length of the lens is $12.0 \mathrm{~mm}$. The $5.5-\mathrm{mm}$-long lens optic has a $360^{\circ}$ square edge design, designed for placement in the capsular bag. This lens is offered in power options in 0.25 -D steps across the +18 to $+25 \mathrm{D}$ range, allowing more precise power correction. ${ }^{1}$

Although the Softec HD intraocular lens has been implanted in Europe since 2005, it was approved by the US Food and Drug Administration (FDA) in April 2010. This report summarizes the available information on the key characteristics of Softec HD IOLs, including biocompatibility, precision, optical clarity, and stability.

\section{Advantages of hydrophilic acrylic material}

Despite a decade of popularity elsewhere, hydrophilic acrylic IOLs have not gained popularity in the US due to several early reports of calcification and opacification..$^{2-9}$ Recently, a new generation of hydrophilic acrylic IOLs has been approved by the FDA and is now available for clinical use in the US.

Hydrophilic acrylics offer physical, biological, and optical qualities that make them suitable for use in foldable IOLs. These characteristics include the following:

1. Less dysphotopsia: Hydrophilic acrylic IOLs have higher water content and therefore a decreased refractive index relative to hydrophobic IOLs, minimizing
Correspondence: Majid Moshirfar John A Moran Eye Center, University of Utah, 65 Mario Capecchi Drive, Salt Lake City, UT 84I32, USA

Tel + I $80|58| 2352$

Fax $+180|58| 3357$

Email majid.moshirfar@hsc.utah.edu 


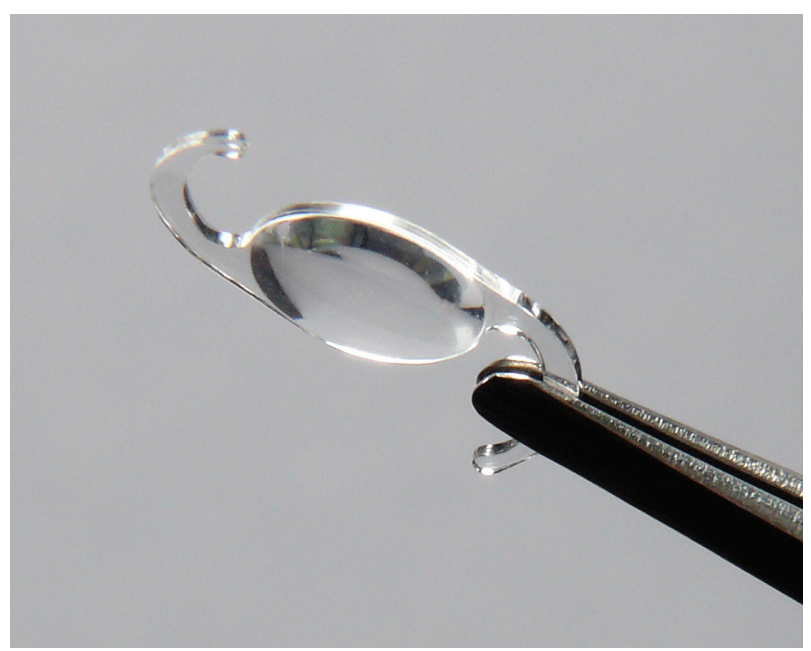

Figure I Softec HD lens (image provided by Lenstec Inc., St. Petersburg, FL, USA).

problems with glare, external and internal reflections, and other unwanted visual phenomena. ${ }^{10-12}$

2. Good biocompatibility: Khan and Percival ${ }^{13}$ followed patients with hydrophilic IOLs for 12 years and reported good flexibility and biocompatibility with minimal inflammatory reaction in the eye. These IOLs have less effect on the blood-aqueous barrier and may be a better option for uveitic and diabetic patients.

3. Good optical clarity: Despite the early reports of calcification in a few types of hydrophilic IOLs, ${ }^{14}$ new hydrophilic IOLs have different copolymer composition, ${ }^{1}$ and there have not been any reports of calcification or glistening in the last 5 years.

4. Resistance to damage during insertion: Hydrophilic acrylic IOLs resist fold marks and forcep damage in contrast to silicone or hydrophobic IOLs.

5. Less susceptibility to biocontamination: Schauersberger et $\mathrm{al}^{15}$ exposed nine different types of IOLs to standardized suspensions of Staphylococcus epidermidis for 5 minutes, then rinsed and tested them for the presence of bacteria. Poly(methyl methacrylate) and hydrophobic IOLs had bacterial densities two or more times higher than hydrophilic IOLs. Schauersberger et $\mathrm{l}^{15}$ concluded that hydrophilicity of IOL material was inversely related to adhesion and bacterial density on the IOL surface.

\section{Advantages of zero aberration aspherical IOLs}

Several studies ${ }^{16-19}$ have shown that aspheric IOLs can provide patients with significant optical benefits over traditional spherical surface IOLs. These optical benefits are due to a reduction in optical aberrations, especially spherical aberration at the retina. The mean corneal spherical aberration is about +0.27 microns $^{20}(90 \%$ of the population have positive corneal spherical aberration, whereas $10 \%$ have negative corneal spherical aberration). ${ }^{21}$

A biconvex IOL with spherical surfaces exhibits positive spherical aberration. Thus, usually, spherical IOLs add positive spherical aberration to the already positive corneal spherical aberration. Aspheric IOLs attempt to improve pseudophakic vision by controlling spherical aberrations. One strategy is to design a lens with negative spherical aberrations to balance the normally positive corneal spherical aberrations. Another strategy is to design a lens with minimum spherical aberrations (symmetric versus asymmetric conic surface) so that no additional spherical aberration is added to the corneal spherical aberrations.

Dr Sarver ${ }^{22}$ used a Kooijman ${ }^{20}$ eye model to compare the performance of different aspheric and spheric design IOLs in different settings, including lens decentration, lens tilt, and photopic and scotopic conditions. In this model, when the lens was centered, the spherical IOL performed worst and the negative spherical aberration IOL performed best. In cases of $1.0 \mathrm{~mm}$ decentration, the spherical surface and negative spherical aberration IOLs did not perform as well as zero aberration IOL designs, even when the trends for decentration did not depend on pupil size or corneal eccentricity. When considering tilting of the IOL, the performance of the IOL designs were comparable in most cases. The zero spherical aberration IOLs outperformed the spherical surface and negative spherical aberration IOLs.

In cases of $0.5 \mathrm{D}$ of defocus at 3.0 and $5.0 \mathrm{~mm}$ pupils, the performances of all IOLs were about equal. The negative spherical aberration IOL showed more contrast for lowfrequency objects than the other IOLs did. The negative spherical aberration IOL showed significant regions of contrast reversal at $5.0 \mathrm{~mm}$ pupils. The equal conic IOL and unequal conic IOL designs appeared to perform about the same.

There are specific conditions in which one IOL design will perform better than another, but, generally, aspheric IOLs perform better than spherical surface IOLs. For the level of alignment errors, zero spherical aberration IOLs perform better than spherical surface IOLs and negative spherical aberration IOLs. The equal and unequal conic IOL designs perform similarly. The equal conic IOL design performs slightly better than the unequal conic IOL design in terms 
of smaller variability in tangential and sagital modulation transfer function (MTF) components in different settings, including decentration and tilt. ${ }^{24}$

\section{Advantages of $0.25 \mathrm{D}$ increments in IOL power}

Approximately 12 to 15 million patients receive an IOL implantation each year. ${ }^{25}$ These patients are becoming increasingly more demanding of higher-quality vision. Advances in surgical technique, better biometry, fourth-generation IOL calculation formulae, and recent advances in IOL design and manufacture have enabled surgeons to routinely achieve a high standard of outcomes.

The International Organization for Standardization (ISO) ${ }^{25}$ has aided by setting standards for IOL manufacturing tolerances. The ISO benchmarks, however, have not been recently updated and tolerate a wide range of variability (Table 1). Although all manufacturers claim to exceed these tolerances, ${ }^{25}$ Lenstec's range of accepted variability is smaller. The Softec HD aspheric lens seeks to create the most accurate aspheric IOL, available in $0.25 \mathrm{D}$ increments from 18.00 to $25.00 \mathrm{D}$. It is also available in $0.50 \mathrm{D}$ increments from 10.50 to $29.50 \mathrm{D}$ and $1.00 \mathrm{D}$ increments from 5.00 to $36.00 \mathrm{D}$.

\section{Lenstec preclinical studies}

Lenstec Inc. performed nonclinical studies on this device in accordance with the ISO 11979 standards for IOLs. ${ }^{26}$

\section{Biocompatibility studies}

Lenstec Inc. conducted a series of in vivo and in vitro acute and chronic toxicity tests to establish the biocompatibility of the lens materials. In summary, the IOL material was nonmutagenic, nongenotoxic, nontoxic, and nonirritant after muscle implantation. The IOL was photostable and nonextractable with a low level of aluminum.

Table I ISO manufacturing tolerance for IOLs versus Lenstec tolerance

\begin{tabular}{lll}
\hline $\begin{array}{l}\text { Range of } \\
\text { diopteric effect }\end{array}$ & $\begin{array}{l}\text { ISO permitted } \\
\text { tolerance }\end{array}$ & $\begin{array}{l}\text { Softec HD } \\
\text { lens }\end{array}$ \\
\hline 0 to $\leq 15 \mathrm{D}$ & $\pm 0.3 \mathrm{D}$ & $\pm 0.125 \mathrm{D}$ \\
$>15$ to $\leq 25 \mathrm{D}$ & $\pm 0.4 \mathrm{D}$ & $\pm 0.125 \mathrm{D}$ \\
$>25$ to $\leq 30 \mathrm{D}$ & $\pm 0.5 \mathrm{D}$ & $\pm 0.125 \mathrm{D}$ \\
$>30 \mathrm{D}$ & $\pm 1.0 \mathrm{D}$ & $\pm 0.125 \mathrm{D}$ \\
\hline
\end{tabular}

Abbreviations: ISO, International Organization for Standardization; IOLs, intraocular lenses.

\section{Laboratory studies and manufacturing}

Data from engineering analyses demonstrate the suitability of the material and overall device design for use in IOLs. In summary, dioptric power, imaging quality/resolution, and spectral transmittance were within acceptance criteria. All lenses had an MTF value of greater than 0.43. All dimensions and compression forces were within the designed acceptance criteria. In an eye model, average axial displacement was $0.1 \mathrm{~mm}$, average decentration was $0.152 \mathrm{~mm}$, and average optic tilt was $1.58^{\circ}$.

\section{FDA clinical studies in the US ${ }^{26}$}

The multicenter US Lenstec Softec HD Posterior Chamber Intraocular Lens (PCIOL) Clinical Investigation was conducted at eight clinical centers with Softec HD PCIOL implantations occurring between December 13, 2006 and June 9, 2008. One year postoperative follow-up provides documented evidence of the safety and effectiveness of the Softec HD PCIOL in 390 eyes of 390 study subjects.

\section{Safety results}

The analysis of safety was based on the cohort of 366 patients who were available for the 12-month evaluation. The analysis of safety was based on adverse event rates (Table 2).

\section{Effectiveness results}

The analysis of effectiveness was based on visual acuity on 366 patients at the 12 -month time point. Of those patients implanted with the Softec HD IOL, 97.1\% achieved a best-corrected visual acuity (BCVA) and $96.4 \%$ overall visual acuity of 20/40 or better as compared with the FDA grid (historical controls of $96.7 \%$ and $92.5 \%$,

Table 2 Cumulative adverse events (occurring at any time during the study)

\begin{tabular}{lll}
\hline $\begin{array}{l}\text { Cumulative } \\
\text { adverse event }\end{array}$ & $\begin{array}{l}\text { Softec HD } \\
\text { incidence (\%) } \\
\mathbf{N}=\mathbf{3 6 6}\end{array}$ & $\begin{array}{l}\text { Food and Drug } \\
\text { Administration } \\
\text { grid (\%) }\end{array}$ \\
\hline Hyphema & 0.0 & 2.2 \\
Macular edema & 0.8 & 3.0 \\
Retinal detachment & 0.0 & 0.3 \\
Pupillary block & 0.0 & 0.1 \\
Lens dislocation & 0.0 & 0.1 \\
Endophthalmitis & 0.0 & 0.1 \\
Hypopyon & 0.0 & 0.3 \\
Surgical reintervention & 0.0 & 0.8 \\
\hline
\end{tabular}




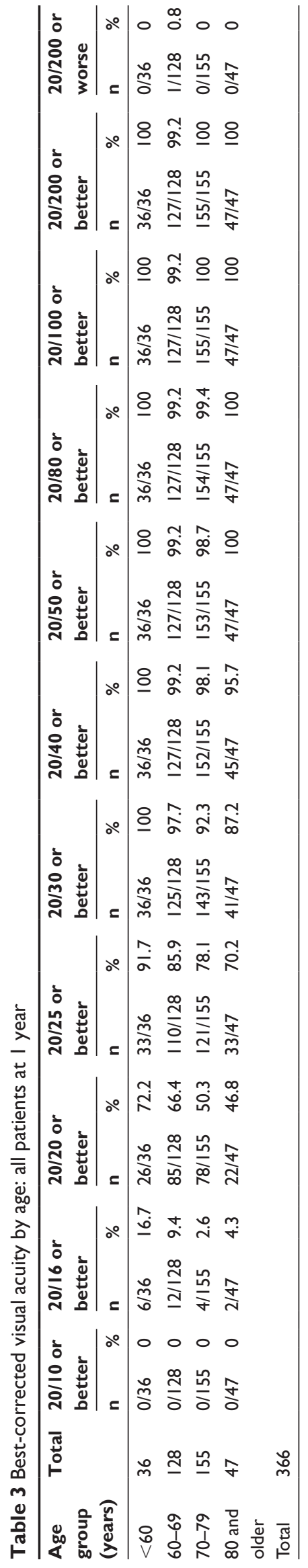

respectively. The rate of $20 / 40$ or better visual acuity for the cohort population exceeded the FDA grid values (Table 3).

\section{Subgroup analyses}

Additional safety analyses were conducted to look for trends that may not be apparent from the overall analysis of the adverse event and best spectacle corrected visual acuity rates. The following clinical data were evaluated.

\section{Best-corrected distance visual acuity: stratified by age (all eyes)}

BCVA stratified by age (age groupings: $<60$ years; 60 to $<70$ years; 70 to $<80$ years; and $\geq 80$ years) at 12-month follow-up. As would be anticipated, the proportion of eyes with BCVA $\geq 20 / 40$ decreased with age: $<60$ years (100\%); 60 to $<70$ years (99.2\%); 70 to $<80$ years $(98.1 \%)$; and $\geq 80$ years $(95.7 \%)$.

\section{Best-corrected distance visual acuity: stratified by adverse event}

The sponsor performed an analysis of the best-corrected distance visual acuity stratified by the presence of any adverse event, or specifically for the presence of a haptic break.

The BCVA of subjects who experienced an adverse event as compared with those who did not was worse with regard to proportion of 20/40 or better vision. At 1 year, $87.5 \%$ in the adverse event group compared with $98.9 \%$ in the nonadverse event group had BCVA of $>20 / 40$. One hundred percent of cases in the adverse event group could see 20/50 or better compared with $98.9 \%$ in the non-adverse event group. For those six study subjects who experienced a haptic break at the time of the Softec HD implantation and then received a Softec PCIOL, the 1 year BCVA was actually better compared with the total study subject population in the Softec HD cohort who did not experience a haptic break: $100 \%$ haptic break group; $98.4 \%$ non-haptic break group seeing $20 / 40$ or better. The occurrence of a haptic break had no impact on visual acuity.

\section{Best-corrected distance visual acuity: stratified by preoperative ocular pathology}

In the patient population, preoperative macular degeneration was present in $3.1 \%$ and other pre-existing conditions existed in 30.5\%. BCVA greater than 20/40 was lower in those study subjects with preoperative ocular pathology 
(94.1\%) compared with the group of study subjects with no preoperative ocular pathology $(98.8 \%)$ at the study endpoint.

\section{Best-corrected distance visual acuity: decrease of two or more lines}

Forty-two subjects were included in a dateline listing of a decrease of two or more lines of BCVA. The distance BCVA was 20/40 or better in 34 of the 42 subjects $(81.0 \%)$. A clinical diagnostic explanation for the decrease in BCVA of two or more lines was identified by the sponsor. Thirty-seven of 42 subjects (88.1\%) had a definitive clinical diagnosis that affected visual acuity. In the five cases with no definitive clinical explanation, the decreases in BCVA were as follows: 20/10 to 20/20 (pre-op 20/30); 20/20 to $20 / 30$ (pre-op 20/25); 20/20 to 20/30 (pre-op 20/50); 20/25 to 20/40 (pre-op 20/50); and 20/25 to 20/40 (pre-op 20/50).

\section{Best-corrected distance visual acuity: stratified by investigator}

There was no statistically significant difference among sites with regard to BCVA $20 / 40$ or better at 12 months $(P=0.24)$.

\section{The future}

There is an increasing expectation for the development of customized aspheric IOLs according to spherical aberration and patient pupil size. With more hydrophilic IOLs launching in the US market, there is anticipation of the marketing of rolling IOLs. Rolling IOLs can be inserted through a $2 \mathrm{~mm}$ incision or smaller, thereby increasing the popularity of microincision cataract surgery.

Unfortunately, as of yet, no clinical study has been conducted with the Softec HD IOL to assess the effect of the aspheric surface on spherical aberration, contrast sensitivity, and visual acuity in different distances and compare this lens with other types of aspherical and spherical IOLs in a randomized clinical trial. Such a future study would allow clinicians to have available to them the information needed to choose an appropriate IOL for each patient.

\section{Disclosure}

The authors have no financial interest in any of the products discussed in this paper.

\section{References}

1. FDA. Lenstec. Available from: http://www.accessdata.fda.gov/cdrh_docs/ pdf9/P090022c.pdf. Accessed December 6, 2010.

2. Izak AM, Werner L, Pandey SK, Macky TA, Trivedi RH, Apple DJ. Calcification on the surface of the Bausch and Lomb Hydroview intraocular lens. Int Ophthalmol Clin. 2001;41(3):63-77.
3. Werner L, Apple DJ, Kaskaloglu M, Pandey SK. Dense opacification of the optical component of a hydrophilic acrylic intraocular lens: a clinicopathological analysis of 9 explanted lenses. $J$ Cataract Refract Surg. 2001;27(9):1485-1492.

4. Buchen SY, Cunanan CM, Gwon A, Weinschenk JI 3rd, Gruber L, Knight PM. Assessing intraocular lens calcification in an animal model. $J$ Cataract Refract Surg. 2001;27(9):1473-1484.

5. Mamalis N. Hydrophilic acrylic intraocular lenses. J Cataract Refract Surg. 2001;27(9):1339-1340.

6. Faschinger CW. Surface abnormalities on hydrophilic acrylic intraocular lenses implanted by an injector. $J$ Cataract Refract Surg. 2001;27(6):845-849.

7. Yu AK, Shek TW. Hydroxyapatite formation on implanted hydrogel intraocular lenses. Arch Ophthalmol. 2001;119(4):611-614.

8. Apple DJ, Werner L, Pandey SK. Newly recognized complications of posterior chamber intraocular lenses. Arch Ophthalmol. 2001;119(4):581-582.

9. Fernando GT, Crayford BB. Visually significant calcification of hydrogel intraocular lenses necessitating explantation. Clin Experiment Ophthalmol. 2000;28(4):280-286.

10. Davison JA. Positive and negative dysphotopsia in patients with acrylic intraocular lenses. J Cataract Refract Surg. 2000;26(9): 1346-1355.

11. Erie JC, Bandhauer MH. Intraocular lens surface and their relationship to postoperative glare. J Cataract Refract Surg. 2003;29(2): 336-341.

12. Erie JC, Bandhauer MH, McLaren JW. Analysis of postoperative glare and intraocular lens design. J Cataract Refract Surg. 2001;27(4): 614-621.

13. Khan AJ, Percival SP. 12 year results of a prospective trial comparing poly(methyl methacrylate) and poly(hydroxyethyl methacrylate) intraocular lenses. J Cataract Refract Surg. 1999;25(10): 1404-1407.

14. Gartaganis SP, Kanellopoulou DG, Mela EK, Panteli VS, Koutsoukos PG. Opacification of hydrophilic acrylic intraocular lens attributable to calcification: investigation on mechanism. Am J Ophthalmol. 2008; 146(3):395-403.

15. Schauersberger J, Amon M, Aichinger D, Georgopoulos A. Bacterial adhesion to rigid and foldable posterior chamber intraocular lenses: in vitro study. J Cataract Refract Surg. 2003;29(2):361-366.

16. Altmann GE, Nichamin LD, Lane SS, Pepose JS. Optical performance of 3 intraocular lens designs in the presence of decentration. J Cataract Refract Surg. 2005;31(3):574-585.

17. Bellucci R, Morselli S, Piers P. Comparison of wavefront aberrations and optical quality of eyes implanted with five different intraocular lenses. J Refract Surg. 2004;20(4):297-306.

18. Packer M, Fine IH, Hoffman RS, Piers PA. Improved functional vision with a modified prolate intraocular lens. J Cataract Refract Surg. 2004; 30(5):986-992.

19. Kershner RM. Retinal image contrast and functional visual performance with aspheric, silicone, and acrylic intraocular lenses. Prospective evaluation. J Cataract Refract Surg. 2003;29(9):1684-1694.

20. Holladay JT, Piers PA, Koranyi G, van der Mooren M, Norrby NE. A new intraocular lens design to reduce spherical aberration of pseudophakic eyes. J Refract Surg. 2002;18(6):683-691.

21. Krueger RR, MacRae S, Applegate R. The future of customization. In: Krueger RR, MacRae S, Applegate R, editors. Wavefront Customized Visual Correction. Thorofare: Slack Incorporated; 2004: 368.

22. Sarver EJ. Theoretical optical performance of an equal conic intraocular lens and comparison to spherical and aspheric IOLs. Powerpoint presentation. Available from http://www.lenstec.com/lenstec/menu_hd.html. Accessed December 25, 2010.

23. Atchison D, Smith G. Optics of the Human Eye. 1st ed. Maryland Heights: Butterworth-Heinemann; 2000:255.

24. Lenstec. World's most accurate aspheric IOL. Available from: http:// www.lenstec.com/lenstec/menu_hd.html. Accessed 2010 Dec 6. 
25. Stewart P. Meeting higher patient expectations with the Softec HD: the major advantages of this lens are its $0.25 \mathrm{D}$ increments and stated manufacturing tolerances. Cataract Refract Surg Today (Europe). 2007 Oct:68-70.
26. FDA. Summary of safety and effectiveness data. Available from: http:// www.accessdata.fda.gov/cdrh_docs/pdf9/P090022b.pdf. Accessed December 6, 2010.

\section{Publish your work in this journal}

Clinical Ophthalmology is an international, peer-reviewed journal covering all subspecialties within ophthalmology. Key topics include: Optometry; Visual science; Pharmacology and drug therapy in eye diseases; Basic Sciences; Primary and Secondary eye care; Patient Safety and Quality of Care Improvements. This journal is indexed on PubMed

Submit your manuscript here: http://www.dovepress.com/clinical-ophthalmology-journal
Central and CAS, and is the official journal of The Society of Clinical Ophthalmology (SCO). The manuscript management system is completely online and includes a very quick and fair peer-review system, which is all easy to use. Visit http://www.dovepress.com/testimonials. php to read real quotes from published authors. 